\title{
Decolorization and COD Removal of Reactive Yellow 16 by Fenton Oxidation and Comparison of Dye Removal with Photo Fenton and Sono Fenton Process
}

\author{
T.R.Sundararaman (Corresponding author) \\ Department of Chemical Engineering \\ Adhiparasakthi Engineering College \\ Melmaruvathur - 603 319, India
}

Tel: 91-44-23774493 E-mail: sundararamantr@yahoo.co.in

\author{
Dr. V. Ramamurthi \\ Department of Chemical Engineering \\ Anna University, Chennai - 600025 , India \\ Tel: 91-44-2235-2642 E-mail: ramamur1951@yahoo.co.in \\ Dr. N.Partha \\ Department of Chemical Engineering \\ Anna University, Chennai - 600 025, India \\ Tel: 91-44-22203534 E-mail: npartha62@yahoo.co.in
}

\begin{abstract}
Wastewaters from textile industry contain various pollutants including a high content of organic matter, surfactants, additives and dyes. Dyes have obtained notoriety as hazardous substances, because most of them are toxic and considered to be resistant to biodegradation. Recently, advanced oxidation processes (AOP) have received considerable attention because it is possible to degrade organic compounds and color from wastewaters. This study was performed to investigate the removal of COD and color for Reactive yellow 16 using Fenton oxidation. The comparisons of removal efficiencies were made among Fenton, Photo Fenton and Sono Fenton process. Removal of COD and color of $80 \%$ \& $90 \%, 90 \% \& 98 \%$, and $82 \% \& 95 \%$ can be achieved by Fenton, Photo Fenton and Sono Fenton process. The results showed that $\mathrm{H}_{2} \mathrm{O}_{2} / \mathrm{Fe}^{2+} / \mathrm{UV}$ process was more effective in COD and color removal.
\end{abstract}

Keywords: Ultraviolet, Sono, Advanced oxidation processes (AOPs), Reactive dye, Decolorization Hydrogen peroxide, COD

\section{Introduction}

The problem of colored effluent has been a major challenge and an integral part of textile effluent treatment as a result of stricter environmental regulations. The presence of dyes in receiving media is easily detectable even when released in small concentrations (Little et al., 1974; Nigam et al., 2000). This is not only unsightly but dyes in the effluent may have a serious inhibitory effect on aquatic ecosystems as mentioned above. Commonly applied treatment methods for color removal from dye contaminated effluents consist of integrated processes involving various combinations of biological, physical and chemical decolorization methods (Galindo et al., 2001; Robinson et al., 2001). These integrated treatment methods are efficient but not cost effective. Traditional physical-chemical techniques such as ultra filtration, reverse osmosis, ion exchange and adsorption on various adsorbents (activated carbon, peat, flyash and coal, wood 
chips, silica gel, corncob, barley etc.) have efficiently been used for the purpose of color removal from textile effluents. Activated carbon is the most commonly applied method for color removal

especially for cationic, mordant, and acid dyes and a slightly lesser extent, dispersed, direct, vat, pigment and reactive dyes (Raghavacharya, 1997). Carbon adsorption of dyes is only successful in some classes of dye (ionic type and hydrophobicity) for a given type of carbon in a certain $\mathrm{pH}$ range (Hao et al., 2000). Nevertheless, these techniques are non-destructive, since they just transfer the pollutant from water to solid matrix. Consequently, expensive operations such as regeneration of the adsorbent materials and post-treatment of solid wastes are needed.

Coagulation may not remove highly soluble dyes and it may be good for disperse dyes, but it produces a large quantity of sludge. Some processes are effective within a narrow $\mathrm{pH}$ range, for example $\mathrm{pH}<3.5$ for Fenton's reagent. Ozonation alone is not effective for disperse dyes (Solozhenko et al., 1995). A combination of these processes is necessary to achieve the desirable goal. For example, the degree of the inhibition for a synthetic dye in a biological-activated sludge system has been reduced from $47 \%$ to $10 \%$ after a pretreatment with $\mathrm{O} 3 / \mathrm{UV}$ or $\mathrm{O}_{3} / \mathrm{H}_{2} \mathrm{O}_{2} / \mathrm{UV}$ (Ledakowicz and Gonera, 1999). Advanced oxidation processes $\left(\mathrm{O}_{3}, \mathrm{O}_{3} / \mathrm{H}_{2} \mathrm{O}_{2}, \mathrm{O}_{3} / \mathrm{UV}, \mathrm{H}_{2} \mathrm{O}_{2} / \mathrm{UV}, \mathrm{O}_{3} / \mathrm{H}_{2} \mathrm{O}_{2} / \mathrm{UV}, \mathrm{Fe}^{2+} / \mathrm{H}_{2} \mathrm{O}_{2}\right.$ for the degradation of non-biodegradable organic contaminants in industrial effluents are attractive alternatives to conventional treatment methods. AOPs based on the generation of very reactive and oxidizing free radicals have been used with an increasing interest due to the their high oxidant power. Production of those radicals is achieved either using single oxidants or combinations of ozone, hydrogen peroxide and UV radiation (Glaze and Kang, 1989) and also, with the combination of hydrogen peroxide with ferrous ions in the so-called Fenton's reagent (Walling, 1975). Although AOPs have a significant advantages over conventional treatment methods since chemical oxidation do not result in high amount of either chemical or biological sludge and almost complete demineralization of organics is possible, the main handicap with AOPs lies in the high cost of reagents or energy sources like ultraviolet light (Galindo et al., 2001).

Decolorization of textile effluents is of major environmental concern that remains to be solved. AOPs have been thoroughly and comparatively evaluated for a variety of organic compounds and wastewaters in the past but with several limitations. Also many investigations have demonstrated that AOPs are effectively removing color and partially organic content of dyestuffs (Legrini et al., 1983; Marechal et al., 1997).

\subsection{Principles of $A O P S$}

AOPs have common principles in terms of the participation of hydroxyl radicals that are assumed to be operative during the reaction. Although it is claimed that there are other species involved, the active species responsible for the destruction of contaminants in most cases seems to be the hydroxyl radical (OH.) which is unstable and quite reactive. Due to the instability of $\mathrm{OH}$. radical, it must be generated continuously "in situ" through chemical or photochemical reactions described in the literature (Oliver et al., 2000).Hydroxyl radicals produced in either way of described above may attack organic molecules by abstracting a hydrogen atom from the molecule (Clarke and Knowles, 1982). Carey (1990) described a common pathway for the degradation of organics by the hydroxyl radicals as follows:

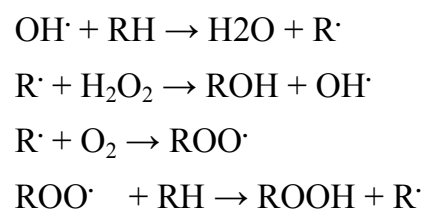

\section{Materials and methods}

\subsection{Experimental setups}

Reactive yellow 16 of commercial grade was used. $\mathrm{HCl}$ and $\mathrm{NaOH}$ analytical grade was used for this study. All the experiments were carried out at room temperature. Fenton oxidation studies were conducted in a one litre beaker. Sample volume for dye solution used was $500 \mathrm{ml}$. After settlement of the sludge, the supernatant was collected for the absorbance measurement and the $\%$ color removal calculated.

Dye Concentration used was $50 \mathrm{mg} / \mathrm{L}$. Concentration of the dye samples were measured at the wavelength of the maximum absorbance $\left(\lambda_{\max }\right)$, which was determined using a UV-Vis spectrophotometer. The percentage removal of a dye was calculated from the absorbance of the supernatant to the standard curve of each dye obtained from its concentration.

Fenton's reagent experiments were carried out at room temperature in a 1 litre reactor using varying hydrogen peroxide and $\mathrm{FeSO}_{4}$ dosages at varying $\mathrm{pH}$ values in order to determine the optimum conditions for best $\mathrm{COD}$ and color removal. Optimum $\mathrm{P}_{\mathrm{H}}$ determination was carried out for chemical dosages of $\mathrm{H}_{2} \mathrm{O}_{2}=900 \mathrm{mg} / \mathrm{lit}$ and $\mathrm{FeSO}_{4}=1000 \mathrm{mg} / \mathrm{lit}$. In order to find optimum chemical dosages at a predetermined optimum $\mathrm{pH}, \mathrm{H}_{2} \mathrm{O}_{2}$ and $\mathrm{FeSO}_{4}$ dosages varied between 100 and $1000 \mathrm{mg} / \mathrm{lit}$. The solutions were mixed by means of magnetic stirrer. 
A photoreactor was set up for the experiments with UV in batch mode operation. A Phillips $250 \mathrm{~W}$ mercury lamp (wavelength of $420 \mathrm{~nm}$ ) was used. After addition of predetermined amount of Hydrogen peroxide and Ferrous sulphate in to the dye sample, the solution within the UV irradiated reactor was mixed by the help of a magnetic stirrer to ensure homogeneous mixture. In addition, both sodium hydroxide and sulphuric acid were used to adjust the $\mathrm{P}_{\mathrm{H}}$.

Sonolysis experiments were performed in a Sono reactor (DU-MINI-120), at an ultrasound frequency of $34 \mathrm{KHz}$ in a continuous wave mode. The power output was $120 \mathrm{~W}$. The volume of solutions sonicated was $500 \mathrm{ml}$. Experiments were carried out under atmospheric conditions and at room temperature.

\section{Results and Discussions}

\subsection{Fenton oxidation of dye solutions}

It is known that the dye removal efficiency by Fenton oxidation is not affected by $\mathrm{pH}$ changes in the range of 2-7.However, the Fenton oxidation is not applicable to alkaline solutions, when $\mathrm{pH}>8, \mathrm{Fe}^{2+}$ ion begins to form floc and precipitates and $\mathrm{H}_{2} \mathrm{O}_{2}$ is also unstable and may decompose to give oxygen and water, and finally loses its oxidation ability. Most studies show that $\mathrm{pH}$ between 2 and 3 is the most effective in the degradation reactions.

The effects of $\mathrm{Fe}^{2+}, \mathrm{H}_{2} \mathrm{O}_{2}$ dose were investigated and the molar ratios of $\mathrm{Fe}^{2+}$ and $\mathrm{H}_{2} \mathrm{O}_{2}$ were optimized. Firstly, in order to investigate the effect of $\mathrm{Fe}^{2+}$ concentration on the dye degradation, experiments were conducted at different $\mathrm{Fe}^{2+}$ concentration and at fixed $\mathrm{H}_{2} \mathrm{O}_{2}$ concentrations of $900 \mathrm{mg} /$ lit for reactive yellow 16. Fig. 3 shows the COD and dye removal as a function of the concentration of $\mathrm{Fe}^{2+}$. The trends of $\mathrm{COD}$ removal according to $\mathrm{Fe}^{2+}$ dose were similar with those of dye removal as shown in Fig.4. The highest COD and dye removals were showed at $1 \mathrm{~g} / \mathrm{lit}$ of $\mathrm{Fe}^{2+}$ concentration for reactive yellow 16 . The COD and dye removal efficiencies of reactive dyes are $80-90 \%$, respectively. After the optimal $\mathrm{Fe}^{2+}$ addition the higher addition of $\mathrm{Fe}^{2+}$ resulted in a brown turbidity that causes the

recombination of hydroxyl radicals and $\mathrm{Fe}^{2+}$ reacts with hydroxyl radicals as a scavenger. Therefore, the COD removal could decrease . The main cost of Fenton reaction process is the cost of $\mathrm{H}_{2} \mathrm{O}_{2}$. So, it is important to optimize the amount of $\mathrm{H}_{2} \mathrm{O}_{2}$ in the Fenton oxidation. The COD and dye removals as a function of $\left[\mathrm{H}_{2} \mathrm{O}_{2}\right]$ were presented in Fig. 5 and 6. The results indicate that the removals of $\mathrm{COD}$ and dye increase with the increase in the $\left[\mathrm{Fe}^{2+}\right]$ and $\left[\mathrm{H}_{2} \mathrm{O}_{2}\right]$ concentrations. Then, it shows that the fractional degradations of the COD were maximum at $900 \mathrm{mg}$ of $\left[\mathrm{H}_{2} \mathrm{O}_{2}\right]$ for reactive yellow 16. The optimum $\left[\mathrm{H}_{2} \mathrm{O}_{2}\right]$ doses for dye removals are also found to be around $1.15 \mathrm{mM}$ of $\left[\mathrm{H}_{2} \mathrm{O}_{2}\right]$. These values are in agreement with the dose values of $\left[\mathrm{H}_{2} \mathrm{O}_{2}\right]$ for COD removals. The highest removal efficiencies of the COD at a fixed $\left[\mathrm{Fe}^{2+}\right]:\left[\mathrm{H}_{2} \mathrm{O}_{2}\right]$ molar ratio for reactive yellow 16 was $80 \%$, at the optimal $\left[\mathrm{H}_{2} \mathrm{O}_{2}\right]$ doses as aforementioned. The maximum dye removal efficiency was $92.0 \%$. However, further increase in $\left[\mathrm{H}_{2} \mathrm{O}_{2}\right]$ has negligible effects. At higher $\mathrm{H}_{2} \mathrm{O}_{2}$ concentration, there is a competition between the substrate and $\mathrm{H}_{2} \mathrm{O}_{2} \cdot \mathrm{H}_{2} \mathrm{O}_{2}$ in high concentration acts as a scavenger of the hydroxyl radical (HO•) to produce per hydroxyl radical (HO2•) which has much lower oxidation capacities than hydroxyl radical. These results indicate that the efficiencies of Fenton oxidation of reactive dye solutions are higher. In addition, the dye removals by Fenton oxidation were noticeably higher than the COD removal. This can be attributable to fact that the organics, which were decomposed to the smaller organics, still have COD, although the dye solutions were decolorized by the cleavage of critical dye bonds, for example azo double bonds or aromatic ring linkages, as a result of Fenton oxidation.

\subsection{Comparison of Fenton oxidation with photo fenton and sono fenton}

In order to evaluate the characteristics of Fenton oxidation, Photo fenton and Sono fenton, of Reactive dye, the COD and dye amounts removed were determined and compared. With regard to fentons oxidation $80 \%$ COD and $90 \%$ dye were removed at $\mathrm{pH}$ 3.Experiments were conducted in photochemical reactor and Sono chemical reactor at this optimum pH 3. With regard to Photo fenton, $90 \% \mathrm{COD}$ and $98 \%$ dye were removed. With regard to Sono fenton, $82 \%$ COD and $95 \%$ dye were removed. Photo fenton and Sono fenton process, showed higher COD and color removal efficiency compared to fentons oxidation.

\section{Conclusions}

A comparative color and COD removal study combining Fentons oxidation and AOPs, which reveal the merits of green chemistry, was carried out for treating Reactive yellow 16. The following conclusions can be drawn from this study:

(i) AOPs have a superior performance compared to the Fentons oxidation process for the removal of COD and color of Reactive yellow 16. Fenton's oxidation resulted in $80 \% \mathrm{COD}$ and $90 \%$ color removal.

(ii) AOPs resulted over $85 \%$ removal for both COD and color. Among the AOPs $\left(\mathrm{H}_{2} \mathrm{O}_{2} / \mathrm{Fe}^{2+} / \mathrm{UV}, \mathrm{H}_{2} \mathrm{O}_{2} / \mathrm{Fe}^{2+} / \mathrm{Sono}\right)$ studied, the combination of $\mathrm{H}_{2} \mathrm{O}_{2} / \mathrm{Fe}^{2+} / \mathrm{UV}$ appeared to be the most efficient in terms of COD and color removal with $90 \%$ and $98 \%$, respectively. Cost evaluation from the operating cost point of view suggested that Fenton's reagent showed a satisfactory $\mathrm{COD}$ and color removal performance and to be economically more viable choice for Reactive yellow 16 on the basis of $90 \%$ removal. Among the AOPs processes used in this study, photo fenton process appeared to be the most efficient in terms of COD and color removal with $95 \%$ and $98 \%$, respectively. 


\section{References}

Alaton.I.A, Balcioglu.I.A, Bahnemann.D.W. (2002). Advanced oxidation of a reactive dye bath effluent: comparison of O3, H2O2/UV-C and TiO2/UV-A processes, Water Res., 36, 1143-1154.

Aleboyed.A, Aleboyeh.H, Moussa.Y.”a”. (2003). Decolorisation of Acid Blue 74 by ultraviolet/H2O2, Environ. Chem.Lett., 1161-164.

Aleboyed.A, Moussa.Y, Aleboyed.H.”b". (2005). The effect of operational parameters on UV/H2O2 decolorisation of Acid Blue 74, Dyes Pigments, 66, 129-134.

Al-Momani.F, Touraud.E, Degource-Dumas.J.R, Roussy.J,Thomas.O. (2002). Biodegradability enhancement of textile dyes and textile wastewater by UV photolysis, J. Photochem. Photobiol. A:Chem. 153, 191-197.

Alnaizy.R, Akgerman.A. (2000). Advanced oxidation of phenolic compounds, Adv. Environ. Res., 4, $233-244$.

Azbar.N, Yonar.T, Kestioglu.K. (2004). Comparison of various Advanced Oxidation processes and Chemical treatment methods for COD and Color removal of Polyester and acetate fiber dyeing effluent, Chemosphere, 55, 35-43.

Behnajady.M.A, Modirshahla.N, Shokri.M. (2004). Photodestruction of Acid Orange 7(AO7) in aqueous solutions by $\mathrm{UV} / \mathrm{H} 2 \mathrm{O} 2$ : influence of operational parameters, Chemosphere, 55, 129-134.

Galindo, C., Jacques, P., Kalt, A., (2001). Photochemical and photocatalytic degradation of an indigolid dye: a case study of acid blue 74(AB74). J. Photochem. Photobiol.A: Chem.[4], 47-56.

Glaze, W.H., Kang, J.W., (1989). Advanced oxidation processes. Description of kinetic model for the oxidation of hazardous materials in aqueous media with ozone and hydrogen peroxide in a semibatch reactor. Ind. Eng. Chem. Res. $28,1573-1587$.

Hao, O.J., Ki, H., Chiang, P.C., 2000. Decolorization of wastewater. Crit.Rev.Environ.Sci.Technol.30 (4), $449-505$.

Kang.S.F, Chang.H.M. (1997). Coagulation of textile secondary effluents with Fenton's reagent, Water Sci.Technol., $36,(12)$ 215-222.

Kuo.W.G. (1992). Decolorizing Dye waste water with Fenton's Reagent, water Res., Vol 26, No.7, $881-886$.

Kang.S.F, Liao.C.H, HungH.P. (1999). Peroxidation treatment of dye manufacturing waste water in the presence of ultraviolet light and ferrous ions, Journal of Hazardous Materials, 317-333.

Ledakowics.S, Gonera, M., (1999). Optimization of oxidant dose for combined chemical and biological treatment of textile wastewater. Water Res. 33(1), 2511-2516.

Legrini. O., Oliveros.E. Braun, A.M., (1983). Photochemical processes for water treatment. Chem. Rev. 93, $671-698$.

Muruganandham.M, Swamination.M. (2004). Decolorisation of Reactive Orange 4 by Fenton and Photo-Fenton oxidation technology, Dyes Pigments, 63, 315-321.

Nigam, P., Armour, G., Banat, I.M., Singh, D., Marchant, R., (2000). Physical removal of textile dyes and solid state fermentation of dye-adsorbed agricultural residues. Bioresour. Technol. 72, 219-226.

Oliver, J.H., Hyunook, K., Pen-Chi, C., (2000). Decolorization of wastewater. Crit. Rev. Environ. Sci. Technol. 30 (4), 499-505.

Raghavacharya, C., (1997). Colour removal from industrial effluents-a comparative review of available technologies. Chem. Eng. World. 32, 53-54.

Robinson, T., McMullan, G., Marchant, R., Nigam, P., (2001). Remediation of dyes in textile effluents; a critical review on current treatment technologies with a proposed alternative. Bioresour. Technol.77, 247-255.

Schrank.S.G, Jean Nonato Ribeiro Clos Santos, Danillo San to S Souza, Elayne Ernilia Santos Souza. (2007). Decolorization of Vat Green 01 textile dye and textile waste water using $\mathrm{H}_{2} \mathrm{O}_{2} / \mathrm{UV}$ process, Journal of Photo Chemistry and Photobiology, 125-129.

Solozhenko, E.G., Soboleva, N.M., Goncharuk, V.V., (1995). Decolourization azodye solutions by Fenton's oxidation. Water Res. 29 (9), 2206-2210.

Shu.H.Y, Chang.M.C. (2005). "a". Pre-ozonation coupled with UV/H2O2 process for the decolorization and mineralization of cotton dyeing effluent and synthesized C.I. Direct Black 22 wastewater, J. Hazard. Mater., B 121, 127-133.

Shu.H.Y, Chang.M.C. (2005)."b”. Decolorization and mineralization of phthalocyanine dye C.I. Direct Blue 199 using UV/H2O2 process, J. Hazard. Mater., B 125, 96-101.

Shu.H.Y, Chang.M.C."c”. (2005). Decolorization effects of Siz azo dyes by O3, UV/O3 and UV/H2O2 processes, dyes and pigments, 25-31. 
ShuH.Y."d". (2006). Degradation of dye house effluent containing C.I. Direct Blue 199 by processes of ozonation, $\mathrm{UV} / \mathrm{H} 2 \mathrm{O} 2$ and in sequence of ozonation with UV/H2O2, J. Hazard. Mater., 13, 392-98.

Walling, C., (1975). Fenton's reagent revisited. Acc. Chem. Res. 8, 125-131.

\section{GRAPHS}

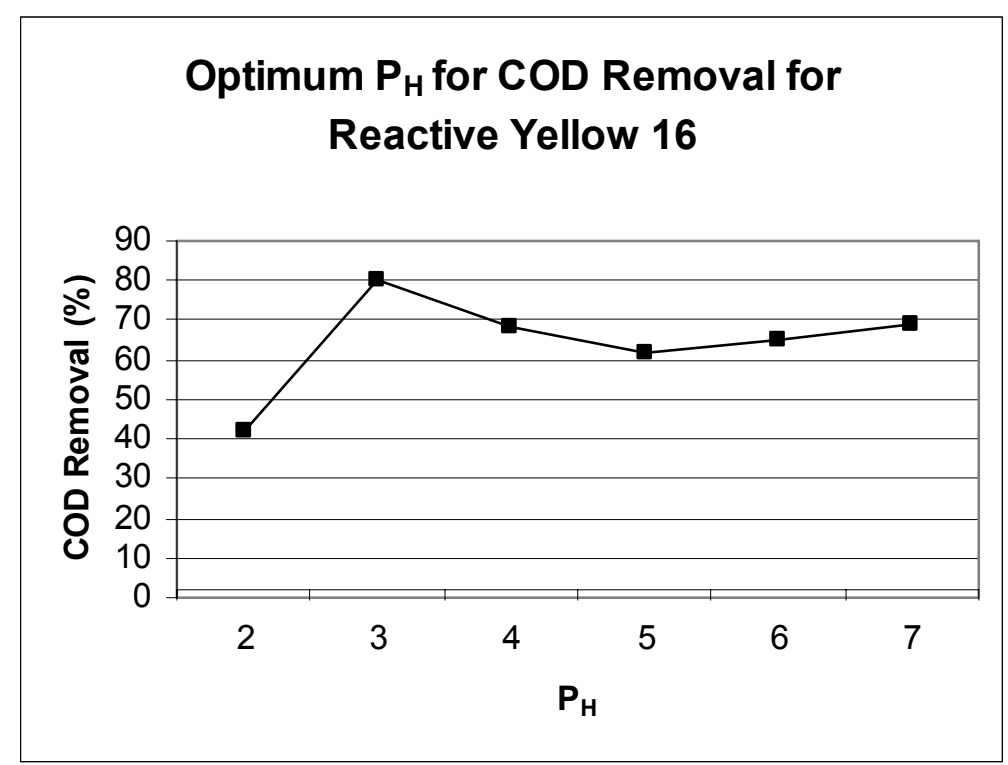

Figure 1. Effect of $\mathrm{pH}\left(\mathrm{C}_{\mathrm{H} 2 \mathrm{O} 2}=0.9 \mathrm{~g} /\right.$ lit and $\left.\mathrm{C}_{\mathrm{FeS} 04}=1 \mathrm{~g} / \mathrm{lit}\right)$ on COD removal in Fenton's process

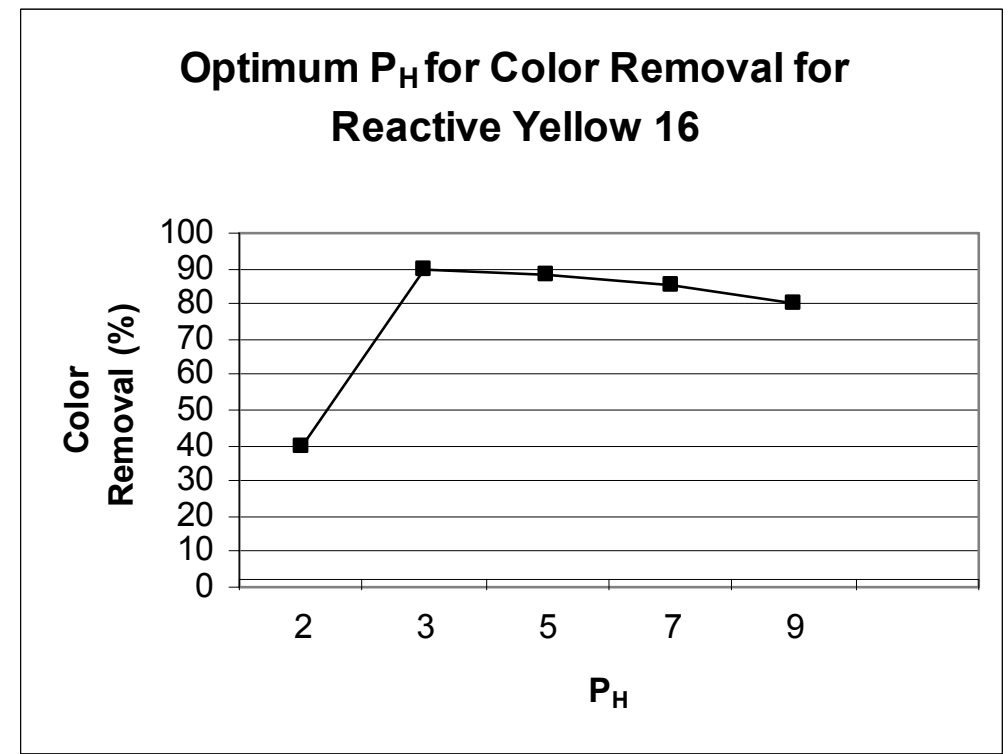

Figure 2. Effect of $\mathrm{pH}\left(\mathrm{C}_{\mathrm{H} 2 \mathrm{O} 2}=0.9 \mathrm{~g} /\right.$ lit and $\mathrm{C}_{\mathrm{FeS} 4}=1 \mathrm{~g} /$ lit $)$ on Color removal in Fenton's process 


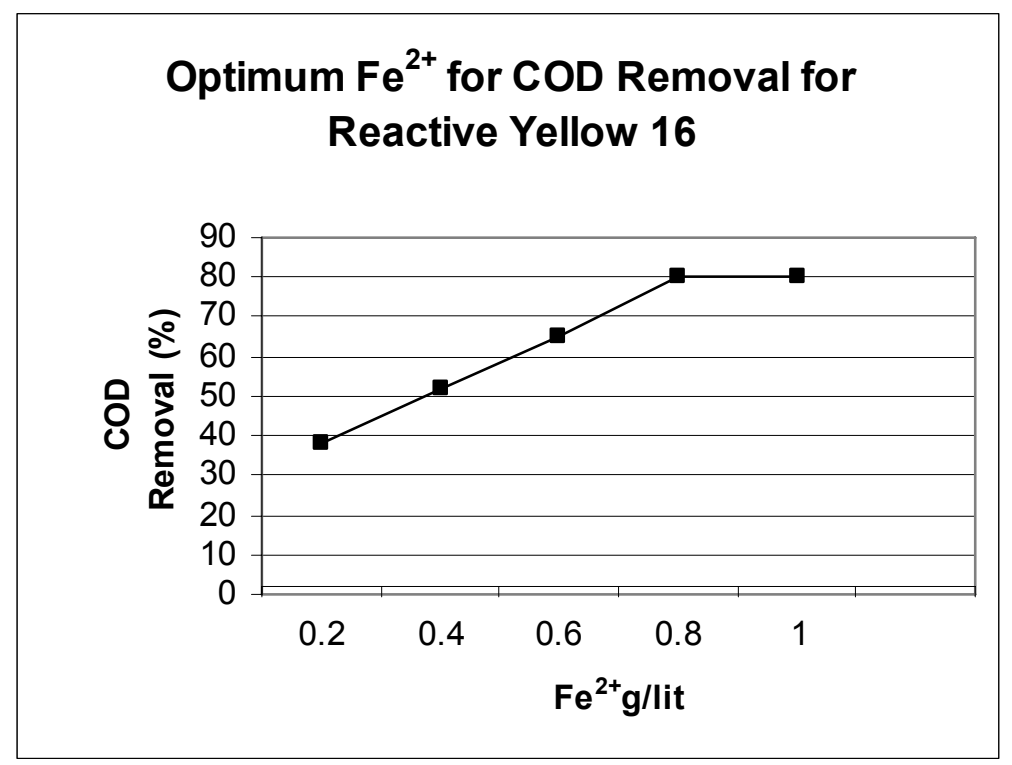

Figure 3. Effect of varying $\mathrm{FeSO}_{4}$ dosages $\left(\mathrm{pH}=3\right.$ and $\mathrm{C}_{\mathrm{H} 2 \mathrm{O} 2}=0.9 \mathrm{~g} /$ lit $)$ on COD removal in Fenton's process

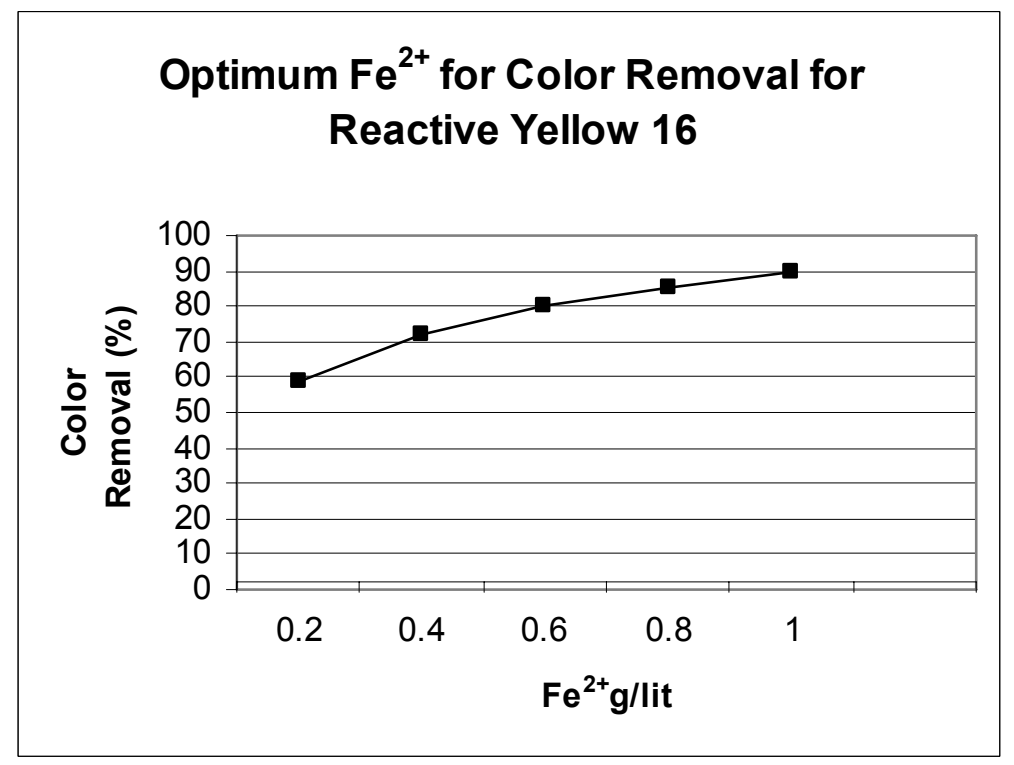

Figure 4. Effect of varying $\mathrm{FeSO}_{4}$ dosages $\left(\mathrm{pH}=3\right.$ and $\mathrm{C}_{\mathrm{H} 2 \mathrm{O} 2}=0.9 \mathrm{~g} /$ lit) on Color removal in Fenton's process 


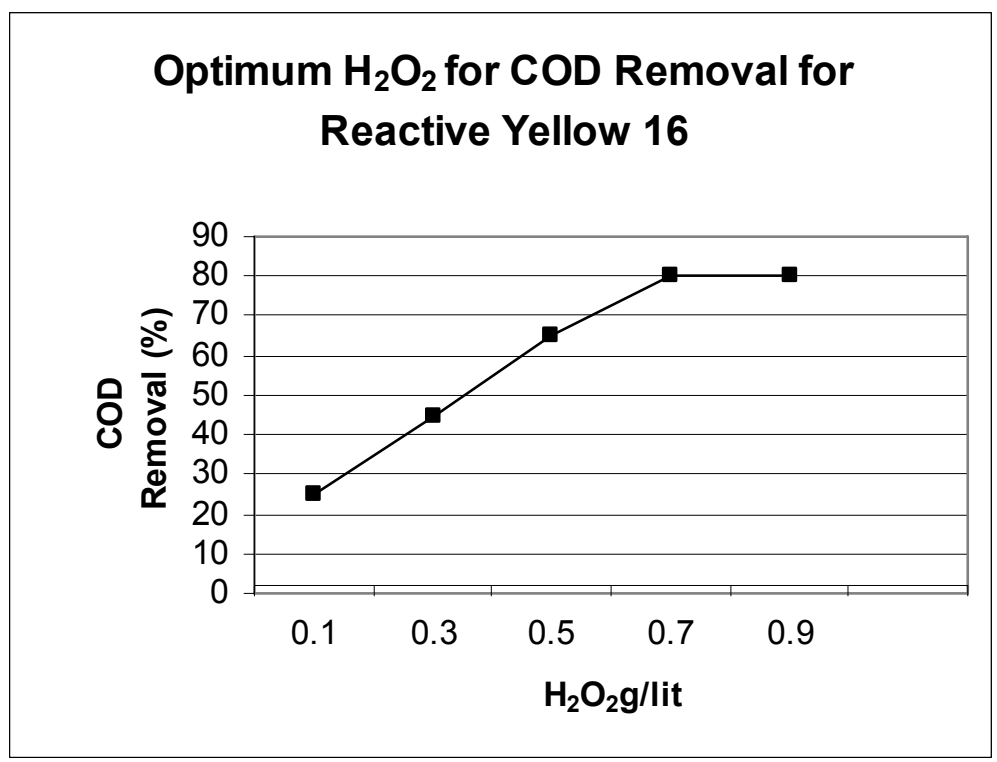

Figure 5. Effect of varying $\mathrm{H}_{2} \mathrm{O}_{2}$ dosages $\left(\mathrm{pH}=3\right.$ and $\mathrm{C}_{\mathrm{FeS} 04}=\mathrm{g} /$ lit) on COD removal in Fenton's process

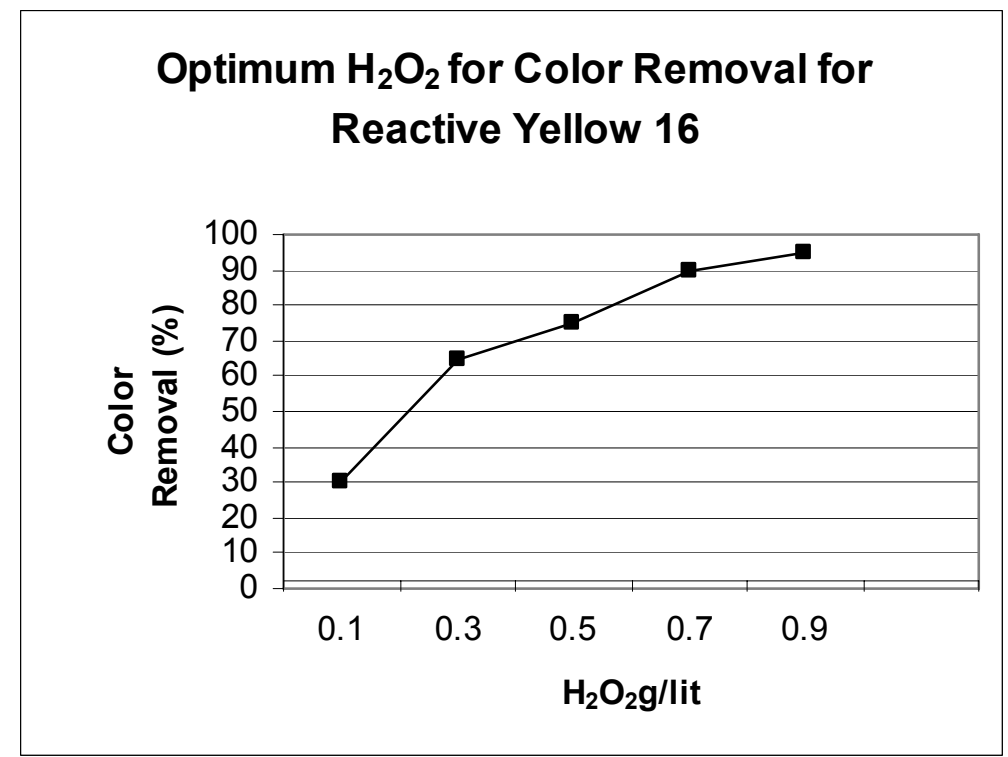

Figure 6. Effect of varying $\mathrm{H}_{2} \mathrm{O}_{2}$ dosages $\left(\mathrm{pH}=3\right.$ and $\mathrm{C}_{\mathrm{FeS} o 4}=1 \mathrm{~g} /$ lit) on Color removal in Fenton's process 


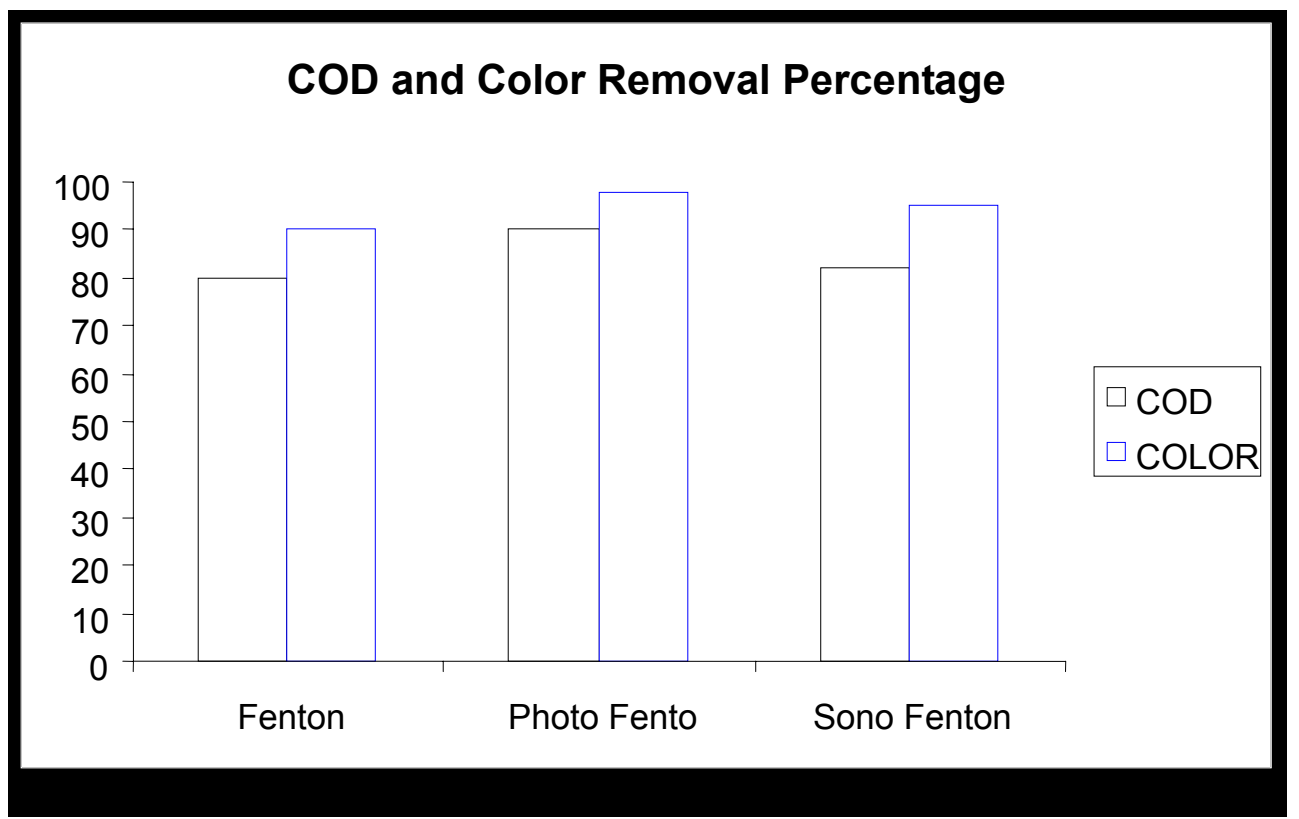

Figure 7. Comparison of Fenton, Photo Fenton, and Sono Fenton process on COD and Color removal 